\title{
Comparisons between Hygroscopic Measurements and UNIFAC Model Predictions for Dicarboxylic Organic Aerosol Mixtures
}

\author{
Jae Young Lee and Lynn M. Hildemann \\ Civil \& Environmental Engineering Department, Stanford University, Stanford, CA 94305, USA \\ Correspondence should be addressed to Jae Young Lee; jaeyoung.lee@alumni.stanford.edu
}

Received 22 February 2013; Revised 15 May 2013; Accepted 9 June 2013

Academic Editor: Lucas Alados-Arboledas

Copyright ( 2013 J. Y. Lee and L. M. Hildemann. This is an open access article distributed under the Creative Commons Attribution License, which permits unrestricted use, distribution, and reproduction in any medium, provided the original work is properly cited.

\begin{abstract}
Hygroscopic behavior was measured at $12^{\circ} \mathrm{C}$ over aqueous bulk solutions containing dicarboxylic acids, using a Baratron pressure transducer. Our experimental measurements of water activity for malonic acid solutions $(0-10 \mathrm{~mol} / \mathrm{kg}$ water $)$ and glutaric acid solutions ( $0-5 \mathrm{~mol} / \mathrm{kg}$ water) agreed to within $0.6 \%$ and $0.8 \%$ of the predictions using Peng's modified UNIFAC model, respectively (except for the $10 \mathrm{~mol} / \mathrm{kg}$ water value, which differed by $2 \%$ ). However, for solutions containing mixtures of malonic/glutaric acids, malonic/succinic acids, and glutaric/succinic acids, the disagreements between the measurements and predictions using the ZSR model or Peng's modified UNIFAC model are higher than those for the single-component cases. Measurements of the overall water vapor pressure for 50:50 molar mixtures of malonic/glutaric acids closely followed that for malonic acid alone. For mixtures of malonic/succinic acids and glutaric/succinic acids, the influence of a constant concentration of succinic acid on water uptake became more significant as the concentration of malonic acid or glutaric acid was increased.
\end{abstract}

\section{Introduction}

The direct and indirect effects of atmospheric aerosols on global climate change have been well established in a number of previous studies. The direct effect is caused by scattering and absorbing solar radiation, and the indirect effect is caused by aerosols acting as cloud condensation nuclei (CCN) (e.g., [1-3]). For both effects, the hygroscopicity of the aerosol plays an important role, since it influences the size of the particle and its ability to become a CCN (e.g., [4-7]).

Atmospheric aerosols consist of inorganic and organic compounds. Organic compounds account for $20 \%$ to $90 \%$ of the total fine particle mass in the troposphere (e.g., $[2,8,9])$. Among the organic aerosol components in the atmosphere, dicarboxylic acids have been frequently measured in previous studies (e.g., [10]). Oxalic acid is the most dominant dicarboxylic acid in aerosols, followed by malonic and succinic acids $[10,11]$. In addition, most dicarboxylic acids are highly soluble in water, which makes them likely to affect the hygroscopic properties of atmospheric aerosols [11-13].

A number of previous studies have measured the water uptake of pure water-soluble organic compounds (e.g., [11,
14-16]) and the water uptake of inorganic and water-soluble organic mixtures (e.g., [17-23]). In the inorganic-organic mixture studies, researchers have reported that the presence of organic compounds can reduce or enhance the hygroscopic growth of pure inorganic compounds. However, only a few studies have measured the hygroscopicity of organic mixtures [19, 24-26].

For an aerosol containing mixed inorganic/organic or organic/organic compounds, water uptake has been most commonly predicted using the Zdanovskii-Stokes-Robinson (ZSR) method [27]. Choi and Chan [19] and Marcolli et al. [24] reported that their measurements agreed well with the predictions made by ZSR method, while Svenningsson et al. [26] showed that the ZSR model was applicable to 3 out of the 4 mixtures they measured.

Another approach uses the UNIFAC (UNIQUAC Functional-Group Activity Coefficients) [28] or a modified UNIFAC [14] model to predict the hygroscopic behavior of a single or mixed organic solution. This method estimates activity coefficients of a system containing various functional groups based on previously determined interaction characteristics among those functional groups. Choi and Chan [19] reported 
that their organic mixture results showed good agreement with the modified UNIFAC predictions. Moore and Raymond [25] reported that measurements of multicomponent mixtures of 5 to 10 dicarboxylic acids were in good agreement with the original UNIFAC predictions while glutaric-malonic mixture data were in good agreement with the modified UNIFAC predictions. However, there is still a dearth of experimental data involving the hygroscopic behavior of organic mixtures, so it is not yet possible to assess the overall reliability of using these models for organic mixtures.

This study examines how mixtures of two water-soluble organics (malonic and glutaric acid) take up water and how the water uptake of a sparingly soluble organic (succinic acid) is affected by the presence of a water-soluble organic (malonic or glutaric acid). To measure the hygroscopic behavior of organic mixtures, this study measured water vapor pressures at $12^{\circ} \mathrm{C}$ over aqueous bulk solutions containing dicarboxylic acids. These measurement data are compared with the predictions made using ZSR and Peng's modified UNIFAC model [14], one of the most frequently used methods for estimating the hygroscopic behavior of organic aerosols.

\section{Experimental Procedures}

2.1. Materials. The organic compounds used in this study are listed in Table 1. For this exploratory study, we focused on 3 species of dicarboxylic acids, a water-soluble chemical group frequently identified in atmospheric aerosols. Malonic acid and glutaric acid were used due to their high solubility, while succinic acid was chosen due to its relatively low solubility. The large odd-even variation in solubility for the dicarboxylic acids is due to the effects of the cis- versus trans-orientation of the end groups on the strength of the intermolecular interactions (e.g., [32]). Table 1 includes the chemical formula, molecular mass $(\mathrm{g} / \mathrm{mol})$, density $\left(\mathrm{g} / \mathrm{cm}^{3}\right)$, solubility ( $\mathrm{g} / 100 \mathrm{~g}$ of water), and manufacturer information.

\subsection{Water Vapor Pressure Measurements. Hygroscopicity was} analyzed by measuring the water vapor pressure over a bulk solution. This bulk solution measurement approach is similar to the one used by previous studies (e.g., [19, 33-35]). The bulk solution method has a couple advantages over two other commonly used methods to measure hygroscopicity, the tandem differential mobility analyzer (TDMA) and the electrodynamic balance (EDB). First, a bulk solution allows for a long residence time, ensuring equilibrium between water and organic compounds. Second, the vapor pressure over a bulk solution can be directly measured using the Baratron under highly controlled temperature conditions. A schematic of our measurement apparatus is illustrated in Figure 1.

An aqueous organic solution sample was prepared by adding Milli-Q purified water (18.2 M). The solid chemicals and liquid water mass were measured by digital balance with uncertainty of $\pm 0.01 \mathrm{~g}$ (less than $1 \%$ of the total mass). The organic solution was mixed by a magnetic Teflon-coated stir bar and stirrer until the chemical was completely dissolved in pure water. This sample solution was placed on a glass vessel manifold and then completely frozen with liquid nitrogen. The headspace air was pumped out using a high vacuum pump (GLD-051, ULVAC, Inc., MA, USA) while the aqueous solution was frozen. After these freeze-and-draw steps, the solution was thawed with a heat gun. All headspace air in the glass vessel manifold was purged by repeating the freeze-draw-thaw steps at least three times and then verifying that the headspace air pressure measured by the Baratron was less than 0.02 Torr. After purging all of the headspace air, the glass vessel containing the aqueous solution was submerged in a thermostat bath controlled by a refrigerated circulator (Neslab RTE-10, Thermo Electron Corp., Inc., NH, USA). The water temperature in the bath was measured with a digital thermometer (Digi Sense RTD Platinum, Eutech Instruments, Singapore). After submerging the glass vessel containing the organic solution, the target temperature, $12^{\circ} \mathrm{C}$, was maintained for at least 30 minutes before the start of measurements, to achieve equilibrium.

The equilibrium water vapor pressure over the organic solution at $12^{\circ} \mathrm{C}$ was monitored by the Baratron pressure transducer (Model 626A, MKS Instruments, Inc., MA, USA) directly. Since the Baratron can only measure the total air pressure in the glass vessel, a quadrupole mass spectrometer (QMS 200, Stanford Research Systems, Inc., CA, USA) was used in parallel, to detect and quantify any organic vapor in the headspace air.

The Baratron and QMS were calibrated using Milli-Q water over a wide range of temperatures to eliminate any systematic error from the measurement setup. The small background signal originating from the mass spectrometer was measured before the experiment and then subtracted from the steady-state reading of the QMS. For the malonic, succinic, and glutaric acids used in this work, no organic vapor was detected by QMS in the headspace air of the glass vessel. As a result, all water vapor pressure values reported in this work are from the Baratron. The equilibrium water vapor pressure was measured independently four times for each solution. The standard deviation of these quadruplicate measurements was determined to be $<0.4 \%$ for the averages reported in this study, so error bars of $0.4 \%$ are used in the figures. Any differences of $0.5 \%$ or more between measurements and model are viewed as significant.

For the physical dimensions (diameter and length) of the capillary used, the optimal performance of the QMS in terms of the detection sensitivity occurs for an inlet pressure of around 10 Torr. Therefore, we chose the solution temperature to be $12^{\circ} \mathrm{C}$ so that the vapor pressure over the bulk solution would be around 10 Torr.

\section{Results and Discussion}

Two approaches were used to measure the hygroscopic behavior of dicarboxylic acid mixtures. The malonic/glutaric acid mixtures were studied by varying concentration levels while maintaining a 50:50 molar mass ratio, due to the high solubility of both compounds. For the malonic/succinic and glutaric/succinic mixtures, a different approach was used, with the concentration of succinic acid held constant while varying the concentration of the second acid. This is because 
TABLE 1: Chemical properties of organic compounds.

\begin{tabular}{|c|c|c|c|c|c|}
\hline Compound name & Chemical formula & Molar mass $(\mathrm{g} / \mathrm{mol})$ & Density $\left(\mathrm{g} / \mathrm{cm}^{3}\right)$ & Solubility $(\mathrm{g} / 100 \mathrm{~g})$ at $25^{\circ} \mathrm{C}$ & Manufacturer \\
\hline Malonic acid & $\begin{array}{c}\mathrm{C}_{3} \mathrm{H}_{4} \mathrm{O}_{4} \\
\left(\mathrm{HOOC}-\mathrm{CH}_{2}-\mathrm{COOH}\right)\end{array}$ & 104.06 & $1.619^{\mathrm{a}}$ & $161^{\mathrm{b}}$ & Alfa Aesar \\
\hline Succinic acid & $\begin{array}{c}\mathrm{C}_{4} \mathrm{H}_{6} \mathrm{O}_{4} \\
\left(\mathrm{HOOC}-\left(\mathrm{CH}_{2}\right)_{2}-\mathrm{COOH}\right)\end{array}$ & 118.09 & $1.572^{\mathrm{a}}$ & $8.8^{\mathrm{b}}$ & Sigma-Aldrich \\
\hline Glutaric acid & $\begin{array}{c}\mathrm{C}_{5} \mathrm{H}_{8} \mathrm{O}_{4} \\
\left(\mathrm{HOOC}-\left(\mathrm{CH}_{2}\right)_{3}-\mathrm{COOH}\right)\end{array}$ & 132.12 & $1.429^{\mathrm{a}}$ & $116^{\mathrm{b}}$ & Alfa Aesar \\
\hline
\end{tabular}

${ }^{\mathrm{a}}$ Lide [29]; ${ }^{\mathrm{b}}$ summarized in Saxena and Hildemann [30].

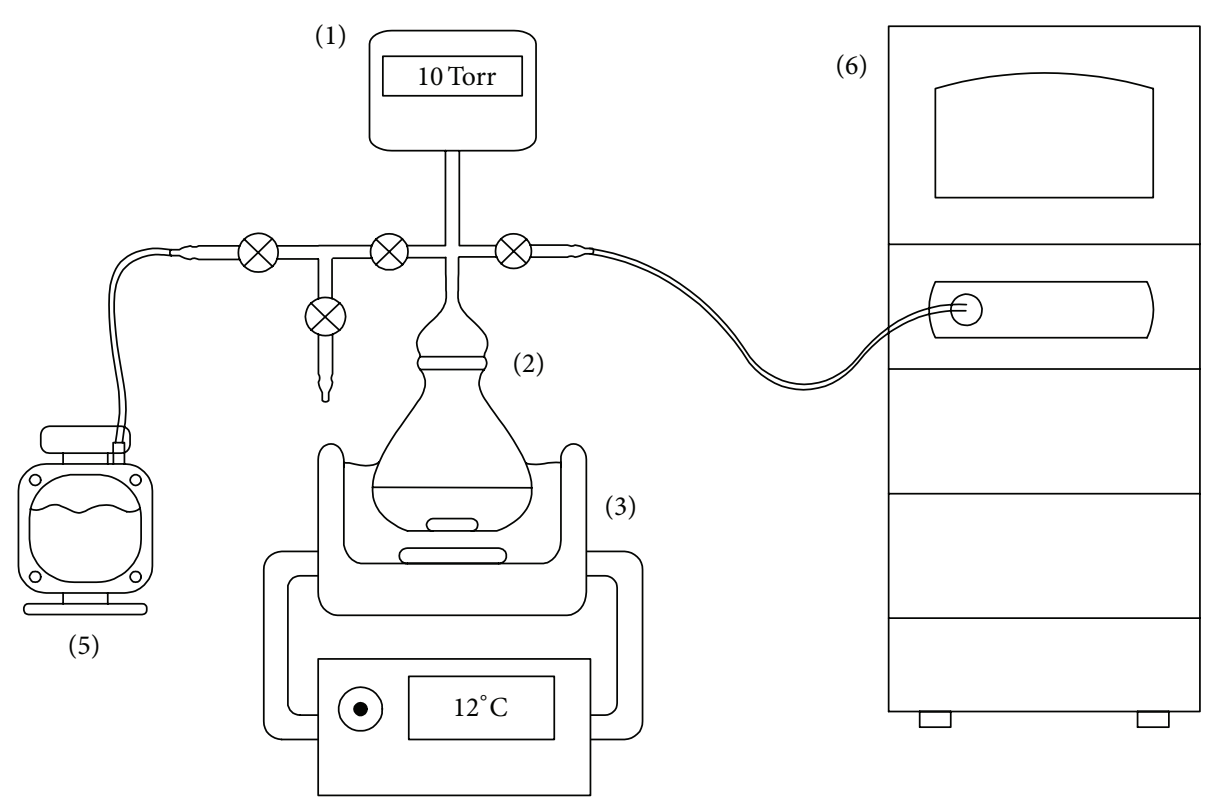

(4)

FIGURE 1: Schematic of water uptake measurement apparatus. This drawing shows the interconnections between (1) Baratron pressure transducer, (2) glass vessel manifold, (3) thermostat bath, (4) refrigerated circulator, (5) high vacuum pump, and (6) quadrupole mass spectrometer (QMS).

succinic acid is less soluble in water than the other two acids. Experimental measurements were compared with the predictions made using ZSR and UNIFAC.

3.1. Single-Component Solutions. For validation of the method and initial comparisons with UNIFAC, water vapor pressure was measured over single-component organic solutions. The water activity of a solution is related to the measured pressure via the following equation:

$$
\text { Water activity }\left(a_{w}\right)=\frac{\mathrm{RH}}{100}=\frac{p_{s}}{p_{0}},
$$

where $\mathrm{RH}=$ relative humidity $(\%) ; p_{s}=$ vapor pressure over organic solution; and $p_{0}=$ vapor pressure over pure water.

For the single-component solutions, measurements spanned concentrations from $0.1 \mathrm{~mol} / \mathrm{kg}$ water to near the solubility limits at $12^{\circ} \mathrm{C}(10 \mathrm{~mol} / \mathrm{kg}$ water for malonic acid and $5 \mathrm{~mol} / \mathrm{kg}$ water for glutaric acid). As shown in Figures 2(a) and 2(b), water activity plots for both malonic acid and glutaric acid decrease as the acid concentration increases and agree with other experimental studies. The dotted lines, denoting Peng's modified UNIFAC prediction, agree with our data to within $0.6 \%$ for malonic acid (except for the $10 \mathrm{~mol} / \mathrm{kg}$ water value, which differs by $2 \%$ ) and $0.8 \%$ for glutaric acid. Note that Peng's measurement was taken at $25^{\circ} \mathrm{C}$, while Braban's and ours were taken at around $12^{\circ} \mathrm{C}$. Peng's modified UNIFAC also estimated water activity at $12^{\circ} \mathrm{C}$. However, the variation in water uptake as the temperature increases from $12^{\circ} \mathrm{C}$ to $25^{\circ} \mathrm{C}$ is small for solute molalities of less than $8 \mathrm{~mol} / \mathrm{kg}$ water; for example, for malonic acid, Braban et al. (2003) [11] experimentally observed a decrease in water uptake of $<0.05 \% / C$, while UNIFAC predicts a small increase in water uptake of $<0.02 \% / \mathrm{C}$ with increasing temperature.

The experimentally measured relationship between water activity and solute molality can be used to determine the hygroscopic growth factor $\left(G_{f}\right)$-the ratio between the wet and dry particle diameters-at a specific RH. The following equation $[36,37]$ relates the hygroscopic growth factor $\left(G_{f}\right)$ to the solute molality $\left(m_{s}\right)$ :

$$
G_{f}=\left\{\frac{\rho_{\mathrm{dry}}}{\rho_{\mathrm{wet}}} \frac{m_{\mathrm{wet}}}{m_{\mathrm{dry}}}\right\}^{1 / 3}=\left\{\frac{\rho_{\mathrm{dry}}}{\rho_{\mathrm{wet}}}\left(\frac{10^{3}+\mathrm{MW}_{s} \times m_{s}}{\mathrm{MW}_{s} \times m_{s}}\right)\right\}^{1 / 3},
$$




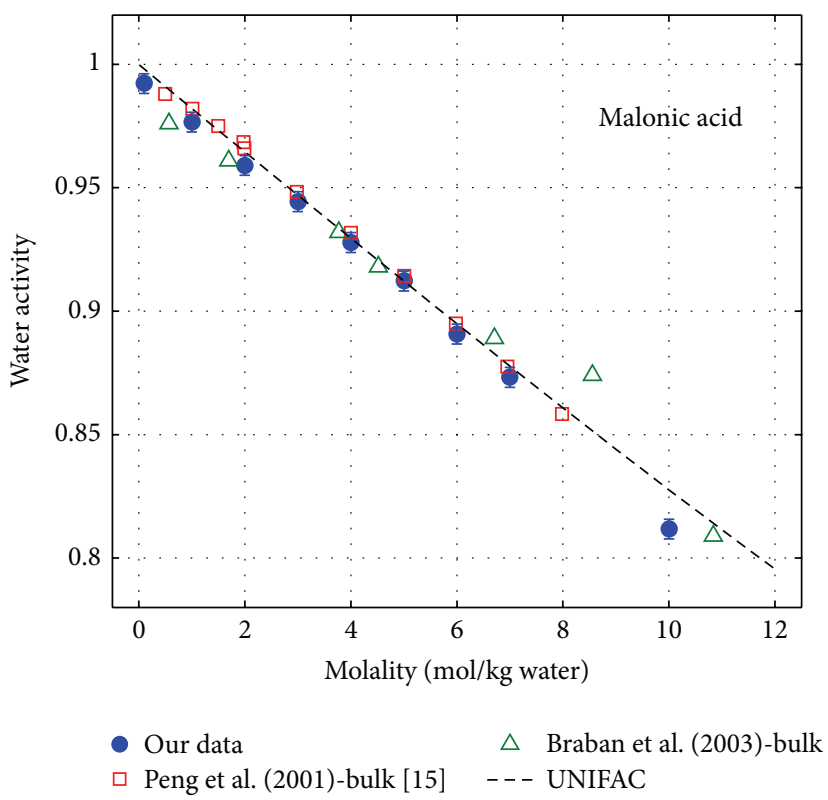

(a)

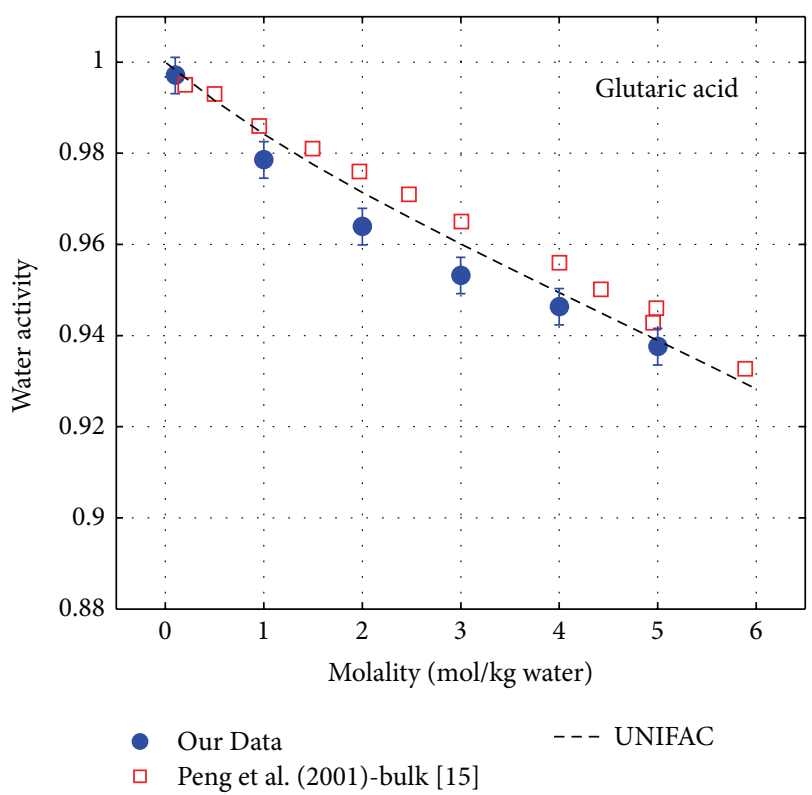

(b)

Figure 2: Water activity of (a) malonic acid and (b) glutaric acid. Each data point represents the average of 4 replicate measurements; error bars on measured data represent standard deviation of $0.4 \%$ (discussed in Section 2). The measurement data by Peng et al. (2001) [14] and Braban et al. (2003) [11] were at $25^{\circ} \mathrm{C}$ and $285.1 \mathrm{~K}\left(=11.95^{\circ} \mathrm{C}\right)$, respectively.

TABLE 2: Growth factors $\left(G_{f}\right)$ for malonic and glutaric acids in this study (at $12^{\circ} \mathrm{C}$ ) versus other studies ${ }^{\mathrm{a}}$.

\begin{tabular}{|c|c|c|c|c|c|c|}
\hline & \multicolumn{2}{|c|}{$G_{f}(85 \%)$} & \multicolumn{2}{|c|}{$G_{f}(90 \%)$} & \multicolumn{2}{|c|}{$G_{f}(95 \%)$} \\
\hline & This study & Other studies & This study & Other studies & This study & Other studies ${ }^{b}$ \\
\hline Malonic acid & 1.43 & $\begin{array}{c}1.40^{\mathrm{d}} ; 1.37^{\mathrm{e}} \\
1.32^{\mathrm{f}} ; 1.28^{\mathrm{g}}\end{array}$ & 1.52 & $\begin{array}{l}1.73^{\mathrm{e}} ; 1.53^{\mathrm{d}} \\
1.52^{\mathrm{g}} ; 1.48^{\mathrm{f}}\end{array}$ & 1.91 & $1.86^{\mathrm{g}} ; 1.84^{\mathrm{d}}$ \\
\hline Glutaric acid & $\mathrm{N} / \mathrm{A}^{\mathrm{c}}$ & $\begin{array}{c}1.15^{\mathrm{e}} ; 1.10^{\mathrm{h}} \\
1.09^{\mathrm{d}} ; 1^{\mathrm{f}}\end{array}$ & $\mathrm{N} / \mathrm{A}^{\mathrm{c}}$ & $\begin{array}{c}1.30^{\mathrm{d}} ; 1.29^{\mathrm{e}} \\
1^{\mathrm{f}}\end{array}$ & 1.59 & $1.49^{\mathrm{d}}$ \\
\hline
\end{tabular}

${ }^{\mathrm{a}} G_{f}$ values for succinic acid are not measurable via bulk solution methods, since its DRH is greater than $95 \%$ at $12^{\circ} \mathrm{C}$.

${ }^{\mathrm{b}}$ Growth factors at $95 \% \mathrm{RH}$ are calculated from their raw data.

${ }^{\mathrm{c}} \mathrm{DRH}$ is greater than $90 \%$ at $12^{\circ} \mathrm{C}$. Therefore, $G_{f}(85 \%)$ and $G_{f}(90 \%)$ are not measurable via bulk solution methods at $12^{\circ} \mathrm{C}$. Values listed from other studies used EDB, TDMA, or bulk solution method at $22-30^{\circ} \mathrm{C}$.

${ }^{\mathrm{d}}$ Peng et al. [14], EDB measurements at $25^{\circ} \mathrm{C}$.

${ }^{\mathrm{e}}$ Prenni et al. [16], TDMA measurements at $30^{\circ} \mathrm{C}$.

${ }^{\mathrm{f}}$ Wise et al. [31], bulk solution measurements at $25^{\circ} \mathrm{C}$.

${ }^{\mathrm{g}}$ Braban et al. [11], $G_{f}$ is calculated from its raw data, bulk solution measurements at $285.1 \mathrm{~K}\left(=11.95^{\circ} \mathrm{C}\right)$.

${ }^{\mathrm{h}}$ Cruz and Pandis [20], EDB measurements at $22-26^{\circ} \mathrm{C}$.

where $m_{\text {wet }}=$ wet particle mass; $m_{\text {dry }}=$ dry particle mass; $\rho_{\text {wet }}=$ wet particle concentration $\left(\mathrm{g} / \mathrm{m}^{3}\right) ; \rho_{\text {dry }}=$ dry particle concentration $\left(\mathrm{g} / \mathrm{m}^{3}\right) ; \mathrm{MW}_{s}=$ molecular weight of solute $(\mathrm{g} / \mathrm{mol})$; and $m_{s}=$ solute molality ( $\mathrm{mol} / \mathrm{kg}$ water).

Table 2 summarizes the $G_{f}$ values calculated at RHs of $85 \%, 90 \%$, and $95 \%$. As can be seen from Table 2, most of our $G_{f}$ values are within the range of those found in, or calculated based on, the previous literature. The $G_{f}$ values for glutaric acid at $85 \%$ and $90 \%$ RH cannot be assessed via our measurement setup. This is because the bulk solution method cannot simulate the particle condition prior to full deliquescence, and the DRH (deliquescence relative humidity) was found to be greater than $90 \%$ at $12^{\circ} \mathrm{C}$-this can be seen via the fact that the water activity is greater than 0.9 at any concentrations of glutaric acid up to the solubility limit (see Figure 2(b)). For comparison, DRH values for glutaric acid at $25^{\circ} \mathrm{C}$ have been reported to be $88.9 \%$ and $88.5 \%$ [14, 31]. Other researchers who reported $G_{f}$ at $85 \%$ and $90 \%$ used an EDB, a TDMA, or a bulk solution method at higher temperature ranges (22$\left.30^{\circ} \mathrm{C}\right)[14,16,20,25]$. Similarly, the $G_{f}$ values for succinic acid are not available even at an RH of $95 \%$, since its DRH is greater than $95 \%$ at $12^{\circ} \mathrm{C}$. Wise et al. [31] and Peng et al. [14] reported DRH values for succinic acid at $25^{\circ} \mathrm{C}$ of $97.6 \%$ and $98.8 \%$, respectively.

3.2. Mixture of Malonic and Glutaric Acids. To study the hygroscopicity of organic mixtures, the water vapor pressure was measured over organic solutions containing malonic acid 


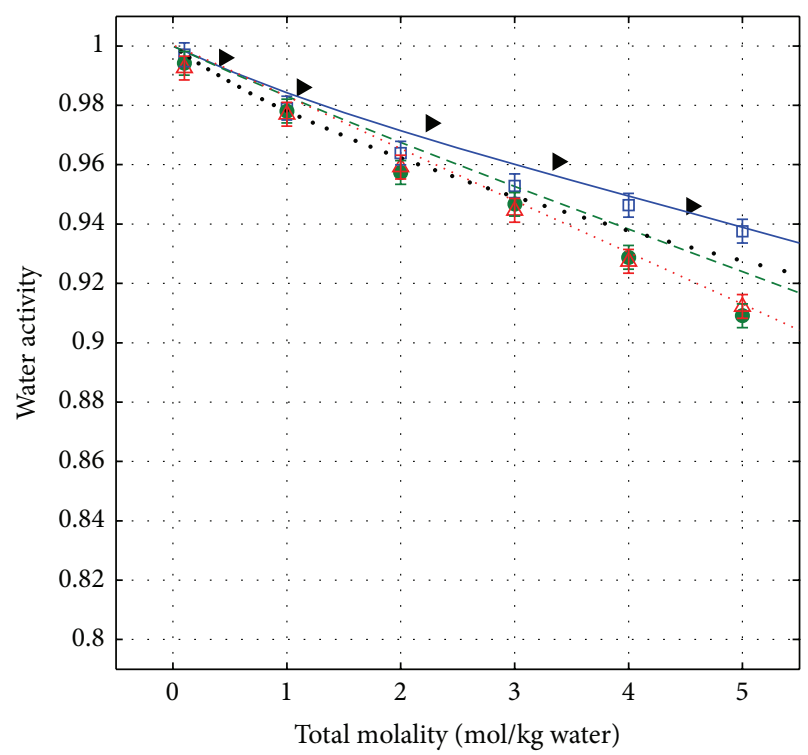

$\square$ Our data, glutaric

- Our data, 50:50 molar mixture

$\triangle$ Our data, malonic

- Choi and Chan [19], 50:50 molar mixture

FIGURE 3: Water activity of malonic acid, glutaric acid and their equal molar mixture. Each data point represents the average of 4 replicate measurements; error bars on measured data represent standard deviation of $0.4 \%$.

and glutaric acid at a 50:50 molar mass ratio. Figure 3 shows our measurements of water activity for the malonic/glutaric acid mixture along with the prediction made by UNIFAC.

Using Peng's modified UNIFAC model for mixtures, this 50 : 50 molar mixture of malonic/glutaric acids was predicted to fall roughly midway between the hygroscopicity of the two individual organics. In the UNIFAC model, the contribution made by one functional group is independent of that made by another, and it systematically predicts a water activity for twocomponent mixtures that is intermediate between the individual dicarboxylic acids. However, in our measurements, the water uptake of this mixed solution closely followed that of malonic acid. This led to a greater water uptake than predicted by the modified UNIFAC model for mixtures. As a result, the measurements were higher than UNIFAC predictions for mixtures of these two acids by up to $1.6 \%$ at $5 \mathrm{~mol} / \mathrm{kg}$ water. Since the standard deviation for each set of 4 replicate measurements was less than $0.4 \%$, the observed discrepancies between our measurements and model predictions reflect a significant difference.

Previously, Moore and Raymond used HTDMA [25] and Choi and Chan used both EDB and the bulk method [19] to measure the hygroscopicity of malonic/glutaric acid mixtures. They reported good agreement between their data and UNIFAC predictions, over a wide range of RH (20$100 \%)$. However, in fact the water activity measurements in the HTDMA and EDB studies were consistently lower than the model predictions by up to $\sim 1-2 \%$, consistent with the decrease found in our study. However, as shown in Figure 3,
Choi and Chan's measurements using the bulk solution method show higher water activities than the model. The cause of this disagreement is unclear; however, it might be due to differences in measurement temperature and/or the method of measuring water activity.

Figure 3 also shows the predictions based on the ZSR mixing rule. The original ZSR [27] equation is given by

$$
\sum_{i} \frac{m_{i}}{M_{i}}=1
$$

where $m_{i}$ is the molality of solute $i$ in a mixture and $M_{i}$ is the molality of the solute when it is alone at a given relative humidity. This equation can be equivalently expressed as the following two equations (e.g., $[20,25])$ :

$$
\begin{gathered}
\text { mass }_{\text {water,mix }}=\sum_{i} \text { mass }_{\text {water }, i} \\
G_{f, \text { mixture }}=\left\{\epsilon \cdot G_{f, \text { malonic }}^{3}+(1-\epsilon) \cdot G_{f, \text { glutaric }}^{3}\right\}^{1 / 3},
\end{gathered}
$$

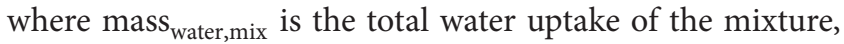
mass $_{\text {water }, i}$ is the water uptake of each species $i$, and $\epsilon$ is the volume fraction of malonic acid in the dry particle. The growth factor of each individual compound was first calculated using (2), and then the growth factor for the mixture was estimated using (5). By converting back to molality, we show in Figure 3 that the predicted ZSR water activity for the mixture lies between those of the individual compounds. This result is due to the assumption that the water uptake of a mixture can be calculated by adding that of each individual compound within the mixture (see (4)). Thus, the ZSR approach overpredicts water activity, compared with our measurements up to $2.3 \%$.

3.3. Mixture of Malonic and Succinic Acids. For mixtures of malonic and succinic acids, we added a set concentration $(0.3 \mathrm{~mol} / \mathrm{kg}$ water $)$ of succinic acid to 1 to $7 \mathrm{~mol} / \mathrm{kg}$ water of malonic acid solution. The concentration of succinic acid was chosen based on its maximum solubility at $12^{\circ} \mathrm{C}$ (see Table 1 for the reported solubility of succinic acid at $25^{\circ} \mathrm{C}$ ). This approach allows an examination of how the hygroscopicity of a set concentration of the less-soluble succinic acid depends on the concentration of malonic acid in the mixture.

As seen in Figure 4, the modified UNIFAC model predicted that the additional amount of water uptake due to addition of succinic acid was essentially a constant increment, regardless of the concentration of malonic acid. However, for our measurements, the influence of the succinic acid on water activity was not significant for 1,2 , and $3 \mathrm{~mol} / \mathrm{kg}$ water of malonic acid solutions (a decrease in water activity of less than $0.2 \%$ ). In contrast, at higher concentrations, the malonic acid solution showed a noticeable decrease in water activity (of $1.0,1.1,1.1$, and $1.4 \%$ for $4,5,6$, and $7 \mathrm{~mol} / \mathrm{kg}$ water of malonic acid, resp.) when $0.3 \mathrm{~mol} / \mathrm{kg}$ water of succinic acid was added. This result again suggests that the noninteraction assumption in UNIFAC can lead to an overestimate of the water activity in dicarboxylic acid mixtures. 


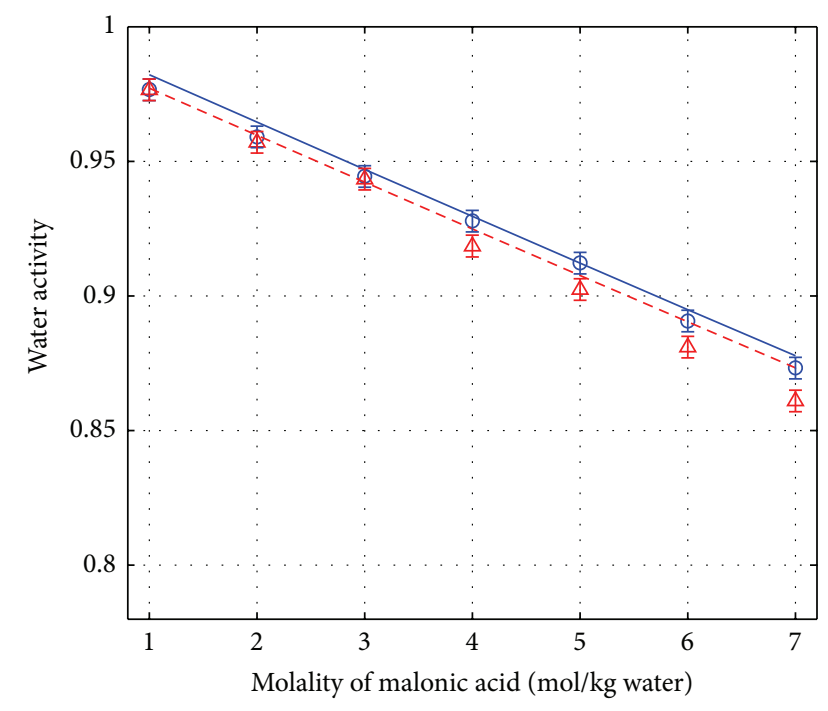

$\begin{array}{lc}\circ \text { Our data, malonic } & \text { UNIFAC, malonic } \\ \begin{array}{c}\text { Our data, malonic w } / 0.3 \mathrm{~mol} \\ \text { of succinic added }\end{array} & -- \text { UNIFAC, malonic w/0.3 mol } \\ \text { of succinic added }\end{array}$

FIGURE 4: Water activity of malonic acid with and without succinic acid added. Each data point represents the average of 4 replicate measurements; error bars on measured data represent standard deviation of $0.4 \%$.

3.4. Mixture of Glutaric and Succinic Acid. We also added $0.3 \mathrm{~mol} / \mathrm{kg}$ water of succinic acid to 1 to $5 \mathrm{~mol} / \mathrm{kg}$ water of glutaric acid solution. The modified UNIFAC model predictions for this mixture assume that the added succinic acid will take up water independently. However, as illustrated in Figure 5, our measurements show that the influence of a given concentration of succinic acid on water uptake systematically strengthened with glutaric acid concentration, although it only became significantly lower (with a decrease of $1.1 \%$ ) at the $5 \mathrm{~mol} / \mathrm{kg}$ level. These results indicate that the amount of water uptake due to succinic acid depends on the concentrations of other organic acids in the solution.

\section{Implications}

We measured hygroscopic properties of three dicarboxylic acid mixtures (malonic/glutaric, malonic/succinic, and glutaric/succinic) using our bulk solution method. Our major findings are as follows.

(1) While our pure malonic and glutaric acids solution data agree with UNIFAC to within $0.6 \%$ (for 0 $7 \mathrm{~mol} / \mathrm{kg}$ water) and $0.8 \%$ (for $0-5 \mathrm{~mol} / \mathrm{kg}$ water), respectively, our measured water activity for mixtures of these two acids is lower than UNIFAC and ZSR predictions, by 1.6 and $2.3 \%$, respectively.

(2) The hygroscopicity of malonic/glutaric acid mixtures closely follows that of pure malonic acid alone.

(3) In organic mixtures, succinic acid's effect on hygroscopicity becomes more pronounced as the concentration of a second, more soluble acid is increased.

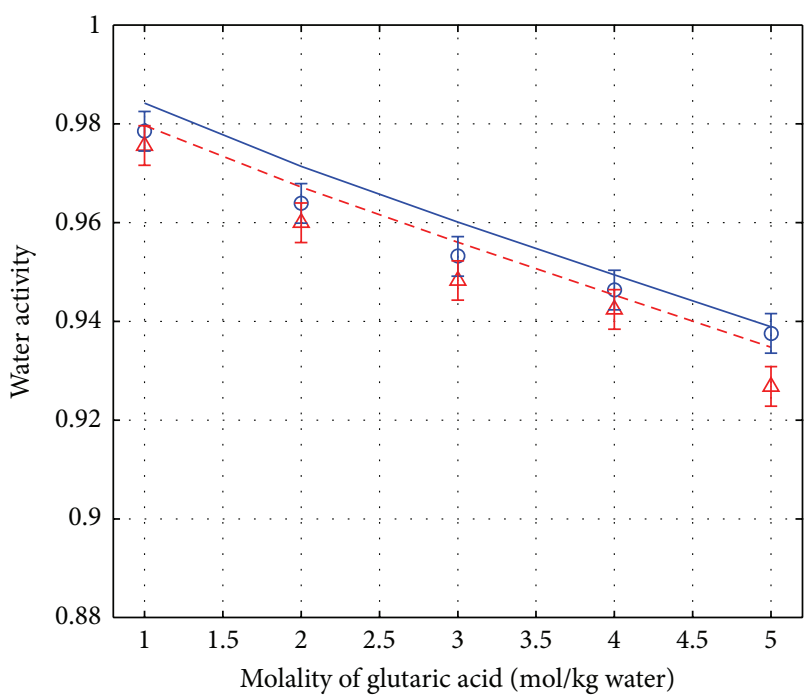

$\triangle$ Our data, glutaric
$\triangle$ Our data, glutaric w/0.3 mol
of succinic added

UNIFAC, glutaric

- - - UNIFAC, glutaric w/0.3 mol of succinic added of succinic added

FIGURE 5: Water activity of glutaric acid with and without succinic acid added. Each data point represents the average of 4 replicate measurements; Error bars on measured data represent standard deviation of $0.4 \%$.

Our findings lend support to the hypothesis that interactions between different species of organics in a mixed solution can cause measurable alterations in hygroscopic behavior.

One possible cause for the trends observed in the hygroscopic properties of these mixtures may involve changes in the surface population of organics. We hypothesize that when two different organic acids are present in solution, they may exhibit a greater tendency to accumulate at the surface, leaving less surface area available for water molecules. Partial support for this hypothesis stems from the hydrophobic behavior of hydrocarbons, as illustrated in Figure 6(a), that is, their tendency to minimize the disruption of hydrogen bonds between water molecules by either staying at the solution surface or staying together [38].

For mixtures of organics in solution, the same mechanism drives less-polar molecules to the surface, or together. However, in this case, driving the different types of acid molecules together is less effective in terms of reducing the contact area and increasing the entropy (Figure 6(b)). As a result, the molecules are more likely to be driven to the surface than to be driven close to each other. Thus when two different organic acids are present in solution, they will exhibit a tendency to accumulate at the surface, leaving less surface area available for water molecules.

This surface population behavior would explain why our measured water activities for the malonic/glutaric mixtures are lower than UNIFAC and ZSR predictions. For the succinic/malonic and succinic/glutaric mixtures, the effect of a set concentration of succinic acid on water vapor suppression increases as the second acid's concentration is increased, suggesting that the number of succinic acid molecules at the surface is increasing. 


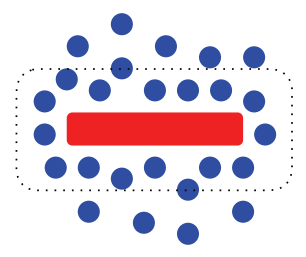

Water molecules near the acid molecules are structured

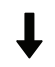

Entropy of water decreased
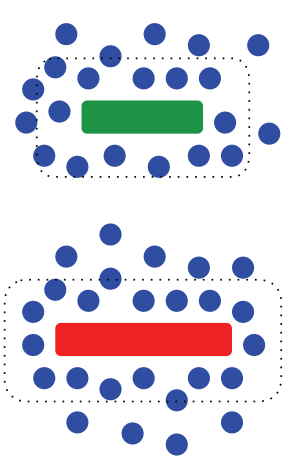

Water molecules are structured

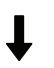

Entropy of water decreased

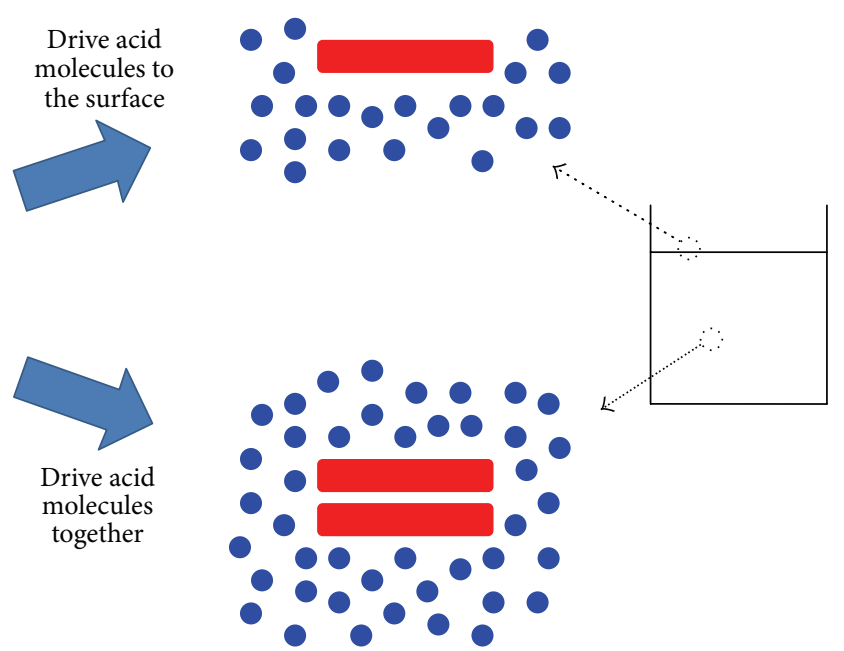

(a)
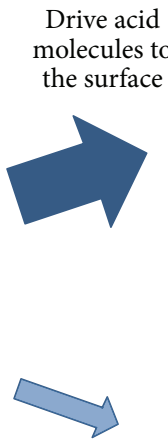

Drive acid molecules together
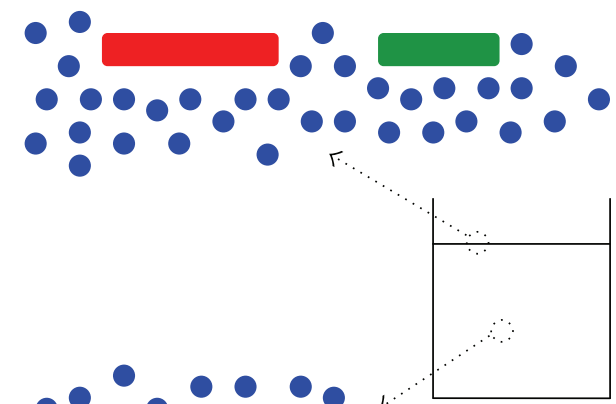

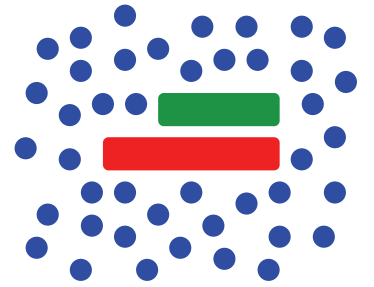

Not effective in terms of reducing the contact area between water and acid molecules

(b)

FIGURE 6: Illustration of hydrophobic effect for (a) a single-compound solution and (b) a mixed solution. The width of each arrow reflects the strength of that pathway.

Our results support the hypothesis that reliable estimates of the hygroscopic behavior of an organic solution mixture cannot be solely based on the behavior of individual organics but must include the interactions between the organics in the solution. Modeling approaches which do not consider species interactions, like UNIFAC and ZSR, were found in our study to systematically overestimate the water activity for dicarboxylic acid mixtures in solution, by up to $2.3 \%$.

\section{Conclusions}

In this study, we observed systematic differences between measured and modeled hygroscopic behavior for three dicarboxylic acid mixtures, over a range of concentrations. While the two-component organic mixtures examined here are much simpler than real atmospheric aerosols, our results suggest that interactions between different organic components must be considered in order to accurately model aerosol hygroscopicity. Further measurements are needed, involving more diverse mixtures of organics and inorganics [39], to better understand and characterize these interactions between species.

\section{Acknowledgments}

Funding for this research came from National Science Foundation (Grant ATM-0731451). The authors would like to 
thank Martin Reinhard and David M. Golden for their help throughout this research.

\section{References}

[1] Intergovernmental Panel on Climate Change (IPCC), "Climate Change 2007: the physical science basis, Working group I contribution to the fourth assessment," Cambridge University Press, 2007.

[2] M. Kanakidou, J. H. Seinfeld, S. N. Pandis et al., "Organic aerosol and global climate modelling: a review," Atmospheric Chemistry and Physics, vol. 5, no. 4, pp. 1053-1123, 2005.

[3] T. Novakov and J. E. Penner, "Large contribution of organic aerosols to cloud-condensation-nuclei concentrations," Nature, vol. 365, no. 6449, pp. 823-826, 1993.

[4] D. S. Covert, R. J. Charlson, and N. C. Ahlquist, "A study of the relationship of chemical composition and humidity to light scattering by aerosols," Journal of Applied Meteorology, vol. 11, pp. 968-976, 1972.

[5] G. Hänel, "The properties of atmospheric aerosol particles as functions of the relative humidity at thermodynamic equilibrium with the surrounding moist air," Advances in Geophysics, vol. 19, no. C, pp. 73-188, 1976.

[6] Y. Kitamori, M. Mochida, and K. Kawamura, "Assessment of the aerosol water content in urban atmospheric particles by the hygroscopic growth measurements in Sapporo, Japan," Atmospheric Environment, vol. 43, no. 21, pp. 3416-3423, 2009.

[7] I. N. Tang, "Chemical and size effects of hygroscopic aerosols on light scattering coefficients," Journal of Geophysical Research D, vol. 101, no. 14, pp. 19245-19250, 1996.

[8] M. O. Andreae and D. Rosenfeld, "Aerosol-cloud-precipitation interactions. Part 1 . The nature and sources of cloud-active aerosols," Earth-Science Reviews, vol. 89, no. 1-2, pp. 13-41, 2008.

[9] J.-P. Putaud, F. Raes, R. Van Dingenen et al., "A European aerosol phenomenology-2: chemical characteristics of particulate matter at kerbside, urban, rural and background sites in Europe," Atmospheric Environment, vol. 38, no. 16, pp. 2579-2595, 2004.

[10] J. Sun and P. A. Ariya, "Atmospheric organic and bio-aerosols as cloud condensation nuclei (CCN): a review," Atmospheric Environment, vol. 40, no. 5, pp. 795-820, 2006.

[11] C. F. Braban, M. F. Carroll, S. A. Styler, and J. P. D. Abbatt, "Phase transitions of malonic and oxalic acid aerosols," Journal of Physical Chemistry A, vol. 107, no. 34, pp. 6594-6602, 2003.

[12] Y. Wang, G. Zhuang, S. Chen, Z. An, and A. Zheng, "Characteristics and sources of formic, acetic and oxalic acids in PM2.5 and PM10 aerosols in Beijing, China," Atmospheric Research, vol. 84, no. 2, pp. 169-181, 2007.

[13] S. Yu, "Role of organic acids (formic, acetic, pyruvic and oxalic) in the formation of cloud condensation nuclei (CCN): a review," Atmospheric Research, vol. 53, no. 4, pp. 185-217, 2000.

[14] C. Peng, M. N. Chan, and C. K. Chan, "The hygroscopic properties of dicarboxylic and multifunctional acids: measurements and UNIFAC predictions," Environmental Science and Technology, vol. 35, no. 22, pp. 4495-4501, 2001.

[15] M. Mochida and K. Kawamura, "Hygroscopic properties of levoglucosan and related organic compounds characteristic to biomass burning aerosol particles," Journal of Geophysical Research D, vol. 109, no. 21, 2004.

[16] A. J. Prenni, P. J. DeMott, S. M. Kreidenweis, D. E. Sherman, L. M. Russell, and Y. Ming, "The effects of low molecular weight dicarboxylic acids on cloud formation," Journal of Physical Chemistry A, vol. 105, no. 50, pp. 11240-11248, 2001.

[17] M. N. Chan and C. K. Chan, "Mass transfer effects on the hygroscopic growth of ammonium sulfate particles with a water-insoluble coating," Atmospheric Environment, vol. 41, no. 21, pp. 4423-4433, 2007.

[18] M. Y. Choi and C. K. Chan, "The effects of organic species on the hygroscopic behaviors of inorganic aerosols," Environmental Science and Technology, vol. 36, no. 11, pp. 2422-2428, 2002.

[19] M. Y. Choi and C. K. Chan, "Continuous measurements of the water activities of aqueous droplets of water-soluble organic compounds," Journal of Physical Chemistry A, vol. 106, no. 18, pp. 4566-4572, 2002.

[20] C. N. Cruz and S. N. Pandis, "Deliquescence and hygroscopic growth of mixed inorganic-organic atmospheric aerosol," Environmental Science and Technology, vol. 34, no. 20, pp. 4313-4319, 2000.

[21] H.-C. Hansson, M. J. Rood, S. Koloutsou-Vakakis, K. Hämeri, D. Orsini, and A. Wiedensohler, " $\mathrm{NaCl}$ aerosol particle hygroscopicity dependence on mixing with organic compounds," Journal of Atmospheric Chemistry, vol. 31, no. 3, pp. 321-346, 1998.

[22] A. J. Prenni, P. J. DeMott, and S. M. Kreidenweis, "Water uptake of internally mixed particles containing ammonium sulfate and dicarboxylic acids," Atmospheric Environment, vol. 37, no. 30, pp. 4243-4251, 2003.

[23] S. Sjogren, M. Gysel, E. Weingartner et al., "Hygroscopic growth and water uptake kinetics of two-phase aerosol particles consisting of ammonium sulfate, adipic and humic acid mixtures," Journal of Aerosol Science, vol. 38, no. 2, pp. 157-171, 2007.

[24] C. Marcolli, B. Luo, and T. Peter, "Mixing of the organic aerosol fractions: liquids as the thermodynamically stable phases," Journal of Physical Chemistry A, vol. 108, no. 12, pp. 2216-2224, 2004.

[25] R. H. Moore and T. M. Raymond, "HTDMA analysis of multicomponent dicarboxylic acid aerosols with comparison to UNIFAC and ZSR," Journal of Geophysical Research D, vol. 113, no. 4, Article ID D04206, 2008.

[26] B. Svenningsson, J. Rissler, E. Swietlicki et al., "Hygroscopic growth and critical supersaturations for mixed aerosol particles of inorganic and organic compounds of atmospheric relevance," Atmospheric Chemistry and Physics, vol. 6, no. 7, pp. 1937-1952, 2006.

[27] R. H. Stokes and R. A. Robinson, "Interactions in aqueous nonelectrolyte solutions. I. Solute-solvent equilibria," Journal of Physical Chemistry, vol. 70, no. 7, pp. 2126-2131, 1966.

[28] A. Fredenslund, R. L. Jones, and J. M. Prausnitz, "Groupcontribution estimation of activity coefficients in nonideal liquid mixtures," AIChE Journal, vol. 21, no. 6, pp. 1086-1099, 1975.

[29] D. R. Lide, CRC Handbook of Chemistry and Physics, Taylor and Francis, Boca Raton, Fla, USA, 89th edition, 2009.

[30] P. Saxena and L. M. Hildemann, "Water-soluble organics in atmospheric particles: a critical review of the literature and application of thermodynamics to identify candidate compounds," Journal of Atmospheric Chemistry, vol. 24, no. 1, pp. 57-109, 1996.

[31] M. E. Wise, J. D. Surratt, D. B. Curtis, J. E. Shilling, and M. A. Tolbert, "Hygroscopic growth of ammonium sulfate/dicarboxylic acids," Journal of Geophysical Research, vol. 108, no. D20, Article ID 4638, 2003. 
[32] H. D. Burrows, "Studying odd-even effects and solubility behavior using $\alpha, \omega$-dicarboxylic acids," Journol of Chemical Education, vol. 69, no. 1, pp. 69-73, 1992.

[33] J. P. D. Abbatt, K. D. Beyer, A. F. Fucaloro et al., "Interaction of $\mathrm{HCl}$ vapor with water-ice: implications for the stratosphere," Journal of Geophysical Research-Atmospheres, vol. 97, pp. 1581915826, 1992.

[34] R. Zhang, P. J. Wooldridge, J. P. D. Abbatt, and M. J. Molina, "Physical chemistry of the $\mathrm{H}_{2} \mathrm{SO}_{4} / \mathrm{H}_{2} \mathrm{O}$ binary system at low temperatures: stratospheric implications," Journal of Physical Chemistry, vol. 97, no. 28, pp. 7351-7358, 1993.

[35] R. Zhang, P. J. Wooldridge, and M. J. Molina, "Vapor pressure measurements for the $\mathrm{H}_{2} \mathrm{SO}_{4} / \mathrm{HNO}_{3} / \mathrm{H}_{2} \mathrm{O}$ and $\mathrm{H}_{2} \mathrm{SO}_{4} / \mathrm{HCl} /$ $\mathrm{H}_{2} \mathrm{O}$ systems: incorporation of stratospheric acids into background sulfate aerosols," Journal of Physical Chemistry, vol. 97, no. 32, pp. 8541-8548, 1993.

[36] A. S. Ansari and S. N. Pandis, "Water absorption by secondary organic aerosol and its effect on inorganic aerosol behavior," Environmental Science and Technology, vol. 34, no. 1, pp. 71-77, 2000.

[37] I. R. Zamora, A. Tabazadeh, D. M. Golden, and M. Z. Jacobson, "Hygroscopic growth of common organic aerosol solutes, including humic substances, as derived from water activity measurements," Journal of Geophysical Research D, vol. 116, no. 23, Article ID D23207, 2011.

[38] P. Joos, Dynamic Surface Phenomena, VSP, Utrecht, The Netherlands, 1999.

[39] J. Y. Lee and L. M. Hildemann, "Surface tension of solutions containing dicarboxylic acids with ammonium sulfate, Dglucose, or humic acid," Journal of Aerosol Science. In press. 

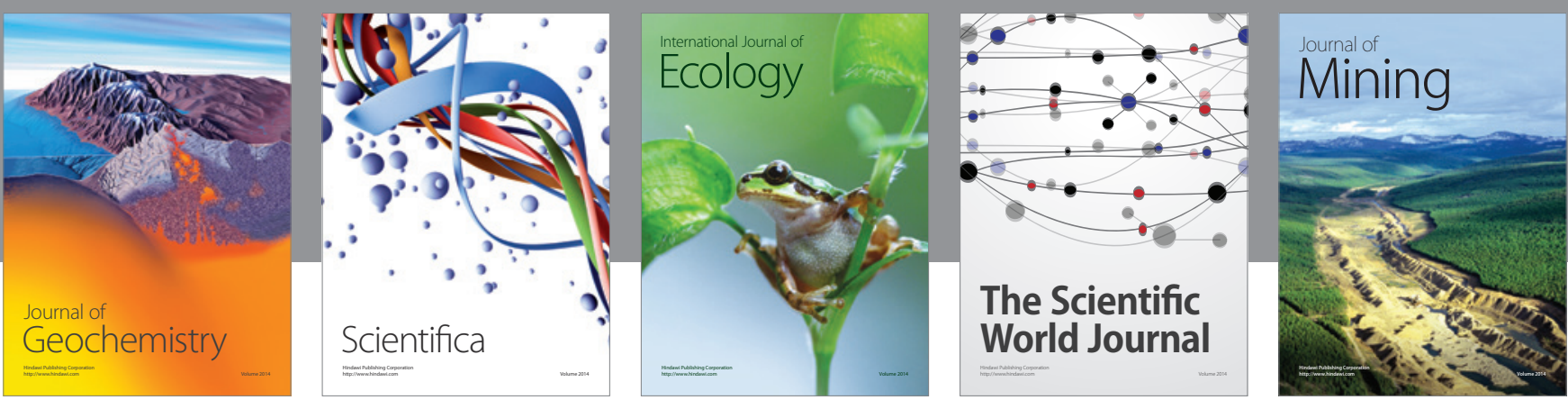

The Scientific World Journal
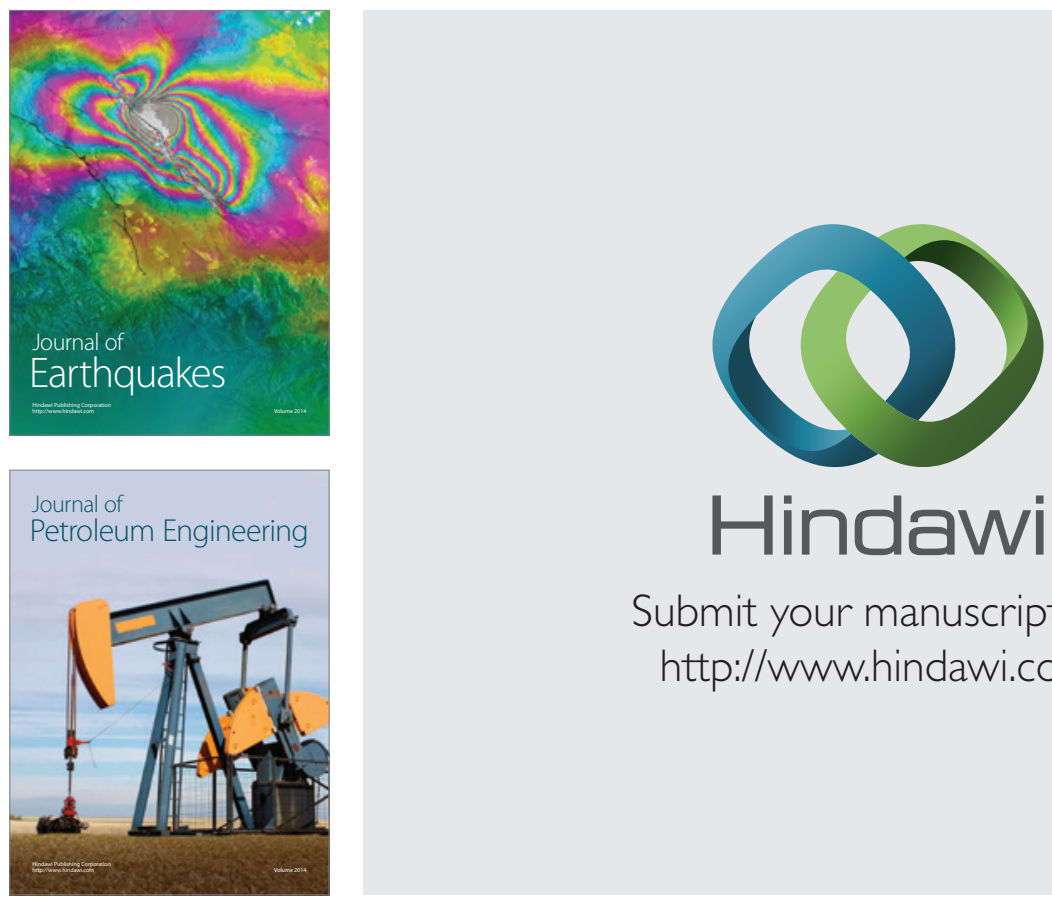

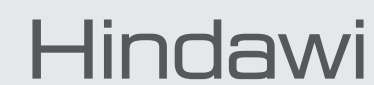

Submit your manuscripts at

http://www.hindawi.com
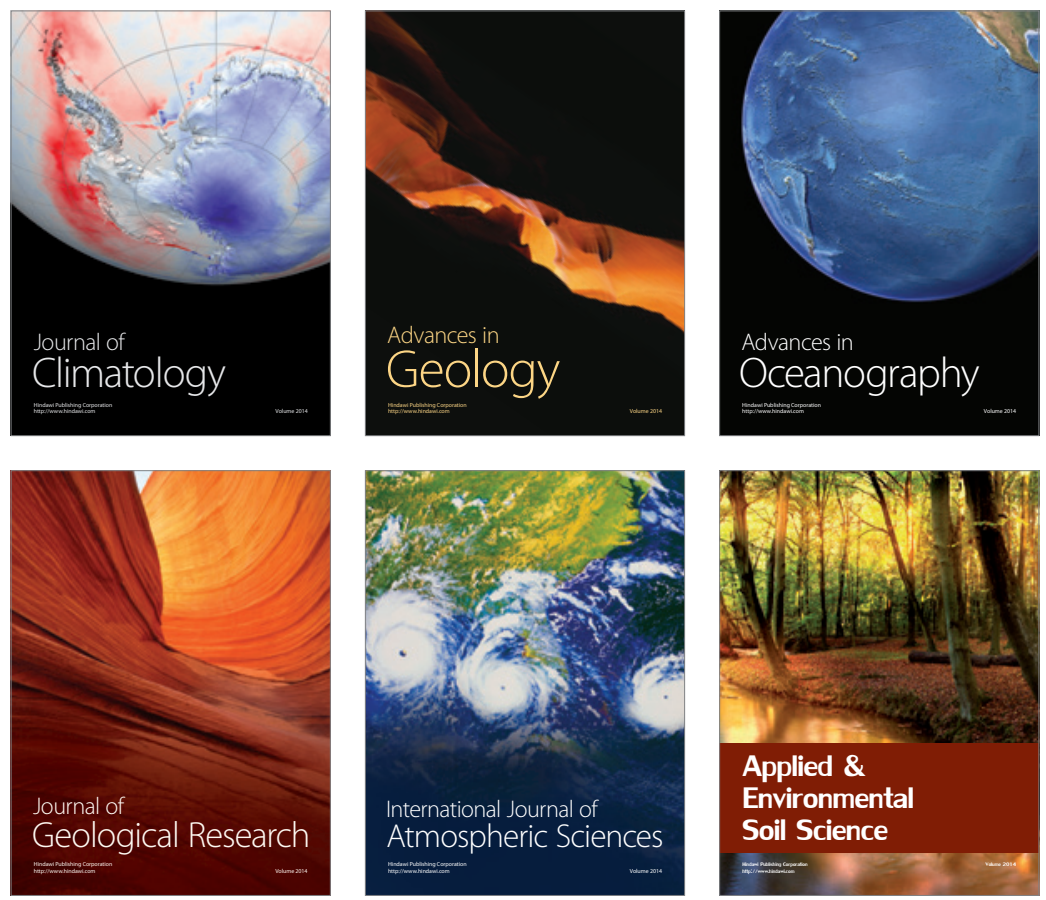
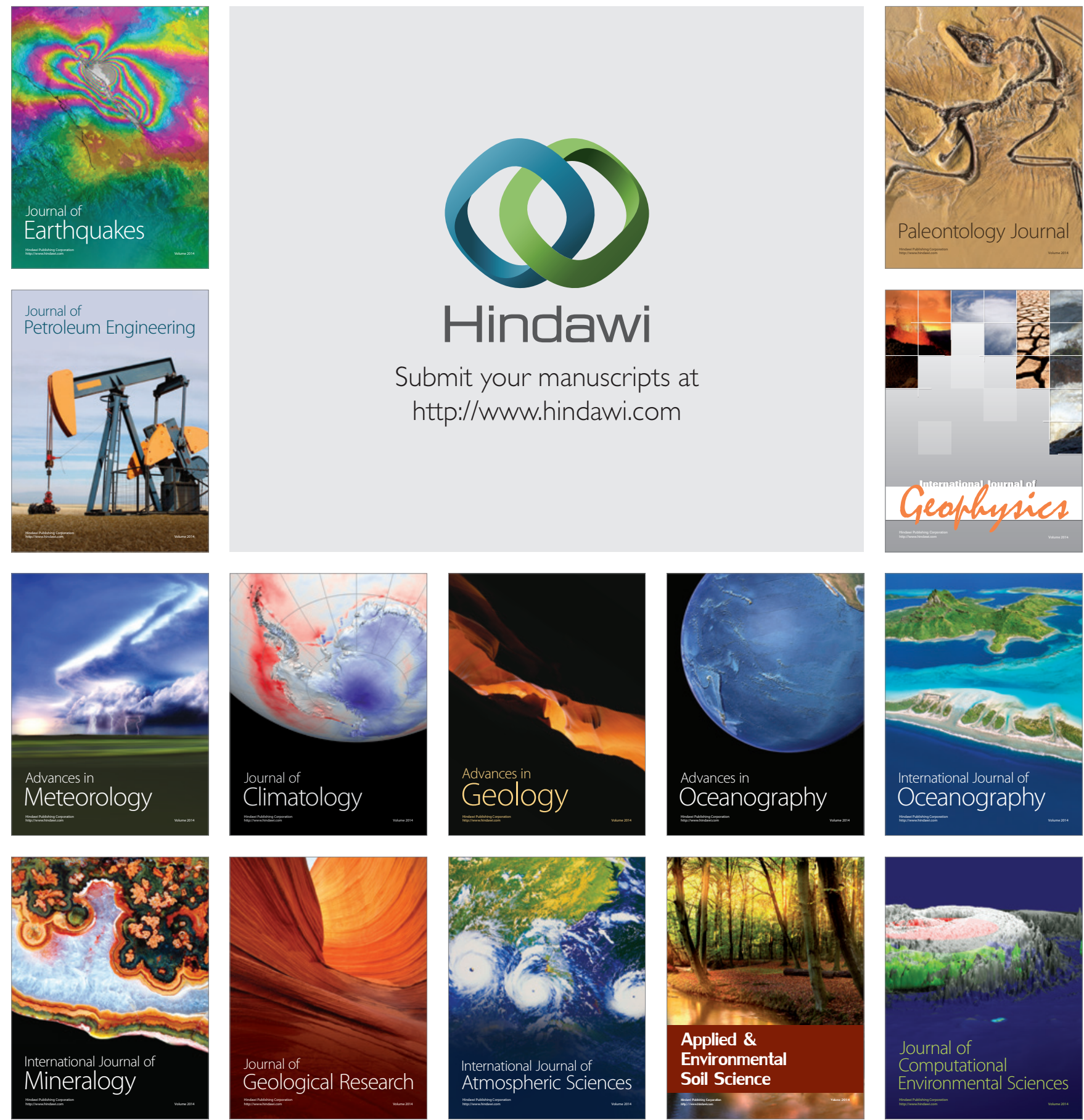